\title{
INDICATIONS AND OUTCOMES OF REPEATED THYROID FINE-NEEDLE ASPIRATIONS: A RETROSPECTIVE EVALUATION FROM A TERTIARY CENTER

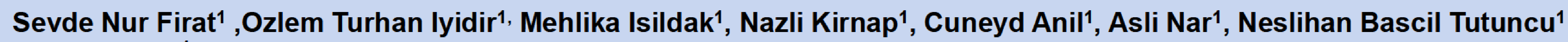 \\ 1: Baskent University Hospital, Department of Endocrinology and Metabolism, Ankara, Turkey
}

\section{BACKGROUND}

Fine needle aspiration (FNA) is the first-line diagnostic test for evaluating thyroid nodules. This test can effectively distinguish between neoplastic and non neoplastic nodules. The Bethesda System suggest that thyroid nodules with non diagnostic (ND), atypia/follicular lesions of undetermined significance (A/FLUS) aspiration should undergo repeat sampling. We aimed to investigate the clinical validity of repeated FNA in the management of patients with thyroid nodules in our institution.

\section{METHODS}

This was a retrospective cohort study of 668 nodules of 529 patients who undergone repeated sampling in Baskent University Hospital between 2000 and 2014. All cytological results were reported accordind to Bethesda system. All patients had an initial examination classified as non-diagnostic, benign, or A/FLUS, and at least one more repeated FNA.

\section{RESULTS}

The majority of patients were female $(n=421, \% 79,6)$. The mean age of patients was $60.1 \pm 14.5$ years. First evaluation revealed that $467(89.9 \%)$ of nodules were benign, $180(26.9 \%)$ were non diagnostic and 21 (3.1\%) were A/FLUS). Enlargement of the nodule (\%27.9) was the most common indication for a repeated sampling followed by non-diagnostic cytology (\%26.9). Reaspiration altered the initial diagnosis in $84.4 \%$ and $66.7 \%$ of the non-diagnostic and (A/FLUS) patients but only in $10.7 \%$ of patients with a benign cytology the initial diagnosis was changed. We evaluated the outcome of patients whose initial and repeated cytological diagnosis are non diagonostic and A/FLUS (Table 1). Outcome data was obtained $23(65.7 \%)$ of these patients.

Table-1: Outcome data of patients with initial and repeated diagnosis of non diagonstic and A/FLUS.

\begin{tabular}{|l|l|l|}
\hline FNA1-FNA2 & Surgery & Repeated Biopsy \\
\hline ND-ND $(n=28)$ & $\begin{array}{l}\text { Nodular hyperplasia-6 } \\
\text { Papillary thyroid ca-2 }\end{array}$ & $\begin{array}{l}\text { Benign-7 } \\
\text { ND-1 }\end{array}$ \\
\hline A/FLUS $(n=7)$ & Nodular hyperplasia-5 & Benign-2 \\
\hline
\end{tabular}

\section{SUMMARY OF CONCLUSIONS}

Enlargement of nodule was the most common indication for a repeated sampling even if the first evaluation was benign. Re-aspiration did not alter the initial diagnosis of benign nodules. Several studies have shown that approximately $90 \%$ to $98 \%$ of patients with an initial benign diagnosis will not change after multiple FNAs, and concluded that routine repeated examinations should not be considered for all patients. Repeat FNA is useful in cases whose initial diagnosis is non diagnostic or A/FLUS, but repeated aspiration for patients with an initial benign examination appears to not increase the expected likelihood of a malignant cytology.

\section{REFERENCES}

1. Graciano AJ et al. Repeated fine-needle aspiration cytology for the diagnosis and follow-up of thyroid nodules. Braz $\mathrm{J}$ Otorhinolaryngol. 2014 Sep-Oct;80(5):422-7

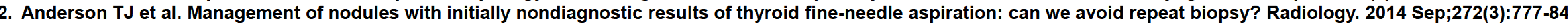

3. Cibas SJ et al. The Bethesda System for Reporting Thyroid Cytopathology. Am J Clin Pathol 2009;132:658-665

4. Popoveniuc $G$ et al. Thyroid Nodules. Med Clin N Am 96 (2012) 329-349 